\title{
Consideraciones sobre la prueba en la doctrina $y$ en nuestro régimen procesal civil
}

\author{
Por el Dr. RICARDO NUGENT.
}

Introducción. - Concepto de la prueba. - El objeto de la prueba. - Clases de pruebas. - Los sistemas de apreciación de la prueba: el sistema de la libre convicción; el sistema de la prueba tasada: el sistema mixto. - Los medics de prueba en nuestro Código de Procedimientos Civiles.

En los tiempos primitivos la defensa de los derechos era la privada. El Estado no existía y por consiguiente los individuos del grupo social, se constituían en defensores de sus derechos, ya sea para repeler el ataque ajeno, o bien con un carácter reivindicatorio para recuperar los bienes de que habían sido despojados. Estos métodos rudimentarios de hacerse justicia por mano propia van cayendo en desuso con el correr de la historix, y poco a poco el Estado se sustituye a los individuos en la ardua tarea de administrar justicia.

En Roma (l) no es posible en un principio la supresión total de la justicia privada, que subsistía en la forma de legítima defensa para repeler la agresión injusta, y también en forma de ataque en caso de fuga del deudor, siendo prohibida en cuanto excediera esos límites. Años más tarde surgiría una reacción más intensa, especialmente durante el imperio de Augusto y finalmente Marco Aurelio establece en forma expresa no sólo sanción penal para quien contraviniendo las leyes imperiales, se hiciera justicia por mano propia, sino otra de orden pecuniario: la pérdida del bien jurídico lesionado.

Esta latente evolución se operó en todos los pueblos antiguos que lograron una organización avanzada, y suprimida la justicia privada el Jefe de la comunidad, imbuído de facultades temporales y teocráticas, se avccas el conocimiento de los litigios que hasta entonces estaban librados a la ley del más fuerte o del más astuto. Culminando este proceso reemplaza el Derecho a la fuerza.

(1) Yors - Derecho privado romøno, Ed. Laba. pág. 514. parag. 2. 
Empero, no sólo es indispensable que la ley reconozca los derechos de la persona humana, porque el simple reconocimiento de estos derechos sin que el titular de los mismos cuente con los medios necesarios para obtener su ejecución, los haría ilusorios y abstractos; era preciso un conjunto de reglas o normas expelitivas que permitieran remediar aquellas situaciones en las cuales se exponía un interés o se desconocía un Derecho.

Surge entonces el Derecho Procesal que define y delimito la función jurisdiccional, establece los órganos adecuados para su ejercicio y señala el procedimiento o rito procesal, no sólo cuando hay controversia o trasgresión de las leyes sustantivas, siro también en aqualias situaciones o hechos que requieren de la presencia de la autoridrd judicial para revestirlos de validez, tales los procedimientos llamados de jurisdicción voluntaria o no contenciosos.

Dentro de este rito procesal la institución de la prueba ocupa lugar destacado. La palabra prueba deriva para algunos de la latina "probe" que quiere decir probo u honrado, porque cuando el actor prueba los hechos que alega se dice que ha procedido en honradez. Para otros proviene de "probandum" que significa demostrar, acreditar. Esta última versión nos parece la más acertada, porque "probar significa hocer conocidos por el Juez los hechos conircvertidos y dudosos y darle la certeza de su modo preciso de ser". (1)

Se han dado muchas definiciones de la prueba. Danty considera que la prueba es una consecuencia legítima que resulta de un hecho evidente cuya certidumbre hace afirmar que otro hecho cuya verdad se ignora, es verdadero o no lo es. Mittermayer sostiene que es la suma de motivos productores de la certidumbre. Domat estima que son todos aquellos medios conducentes a persuadir al espíritu de la verdad. Bonnier afirma que es la demosiración de la conformidad que existe entre nuestras ideas y los hechos de orden físico. (2)

Estas definiciones, como es fácil advertir, encierran un carácter meramonte fliosóíico. La prueba legal es distinta a la filosófica; por ésta se llega a la verdad por cualquier medio; por ıquella, el Juez debe descubrirla basándose en el maierial presentado por las partes, de ahí la máxima "secundum allegata et probcta judex judicare edebet". Para el Juez lo que no está acreditado en autos, no puede ser tomado en consideración.

Para nosotros prueba es simplemente el modo de acreditar la existencia de un hecho, do un acto juridico y excepcionalmente la existencia del derecho y la costumbre.

El objeto de la prueba son los hechos controvertidos y los actos juridicos. Esta es la regla general. En nuestro ordenamiento jurídico se exige en determinados casos la prueba del derecho extranjero y la prueba de la costumbre, por razón de la dificultad que tiene el Juez para su investigación. No obstante, en algunas legislaciones se ha suprimido la prueba de la ley extranjera. Estimamos que es acertada la disposición de nuestra ley procesal, porque evidentemente no puede pretenderse que el Juez por el hécho de ser tal debe conocer obligatoriamente todas las legislaciones foráneas.

(1) Lessona, Teoría General de Ia prueba en el Derecho Civil. Tomo I; pág. 2. parag. 2.

(2) Nicolás Casarino, Derecho de Procedimientos. Ed. Librería Jurídica, 1917. pág. 167. 
La ley nacional no necesita ser probada (Art. 335), ya que si la ignorancia de la ley no excusa de su cumplimiento a los miembros de la colectividad, con mayor razón debe ser conocida por el magistrado cuya misión es precisamente aplicar lá ley. Sólo existe como excepción a este principio la necesidad de probar la ley nacional cuando es impugnada su autenticidad, para lo cual seró necesario la confrontación del texto de la ley cuya autenticidad se impugna, con la autógrafa de la misma.

El Juzgador por regla general no puede basarse para resolver un asunto cualquiera en las simples afirmaciones de las partes, y debe por lo tanto tener a su disposición los medios que le permitan controlar la exactitud de dichas afimaciones. El Juez en el proceso civil no es un investigador, sólo tiene en cuenta las pruebas que le presenton las partes a tal punto que si el demandado conviene en la demanda, el juicio ha terminado y debe proceder a dictar sentencia.

De otro lado, las pruebas no sólo tienen por objeto controlar las afirmaciones de las partes, son además una forma de crear la convicción del juzgador. Al respecto existe una vieja querella doctrinaria que se disputa la primacía de estos dos aspectos de la prueba, querella que por lo demás conceptuamos innecesaria, desde que estos dos aspectos de la prueba lejos de excluirse se complementan.

Nuestro Código de Procedimientos Civiles distingue los juicios de hecho y los de puro derecho. Los primeros requieren de prueba; los segundos no, porque como acabamos de destacar el derecho en principio no necesita ser probado como en tiempos pretéritos. En Grecia, por ejemplo, el Juez no podía fundarse sino en la ley probada por las partes, y entre los medios de prueba se incluía la prueba de la ley. Para Aristóteles las pruebas eran cinco: "Ias leyes, los testigos, los contratos, la tortura de los esclavos y el juramento". Al excluir nuestro ordenamiento jurídico la prueba de la ley nacional, los juicios de puro derecho se sustancian como es obvio, sin abrirse la causa a prueba, de modo que contestada la demanda, se corre traslado a la parte actora para que replique y fecho a la demandada para que duplique, con lo cual queda expedito el juicio para sentencia.

Hemos indicado que los hechos son materia de prueba. Sin embargo es conveniente dejar establecido que no todos los hechos requieren ser probados, como los que no han sido materia de impugnación $y$ en que ha convenido expresamente la contraparte (Art. 339). Consecuencia de esta premisa es que son objeto de prueba los hechos controvertidos. También son objeto de prueba los hechos que aun cuando no han sido impugnados, se han alegado en un juicio que se sigue en rebeldía.

Los hechos notorios y los evidentes tampoco son objeto de pruebr. Los primeros no necesitan ser probados porque importon un conocimiento general, un conocimiento público. No podría pretenderse acreditar en juicio el hesho notorio de la segunda guerra mundial. El concepto de notoriedad no es un concepto absoluto, puede concretarse a uno o varios lugares determinaảos. El movimiento sísnico del 24 de mayo de 1940 ocurrido en nuestra Capitel, es un hecho notorio en el Perú, pero nó en un lejano país euro- 
peo, y en esta eventualidad, al dejar de ser notorio deberá necesariamente ser probado.

Los hechos evidentes són aquellos que no necesitan demostración por su carácter axiomático. En un proceso sería inadmisible pretender acreditar la ley de la gravedad o cualquier otro hecho derivado de los principios científicos.

Precisado el objeto de la prueba surge el problema de la carga de la prueba, o sea a quien corresponde acreditar los hechos que sirven de fundamento a la acción. La carga de la prueba corresponde al que afirma hecho controvertido "actori incumbit probatio" o mejor todavía "actori non probate reus absolvitur". El que no prueba los hechos que debe probar pierde el pleito y puede quitarse esa carga probando los hechos que la ley le indica probar.

Los tradicionales momentos de la prueba son tres: el ofrecimiento o anuncio formal de que la prueba será presentada en su día, a fin de acreditar un hecho determinado. Generalmente el ofrecimiento queda consumado con las frases rituales "ofrezco en parte de prueba........". El segundo momento es el petitorio, o sea la solicitud formulada para la admisión de los medios de prueba, que como se aprecia se confunde en nuestra legislación con el ofrecimiento $\mathrm{y}$ sólo se advierte la diferencia, cuando se pide el señalamiento de nuevo día y hora para la actuación de la prueba, petición que en esta oportunidad es distinta del ofrecimiento. El tercer momento es el diligenciamiento que "consiste en el conjunto de actos procesales que es menester cumplir para trasladar hacia el juicio los distintos elementos de convicción propuestos por las partes" (3). El diligenciamiento se empieza a actuar cuando el Juez accede a la petición, señalando día y hora para la realización de la diligencia, la que se perfecciona con la redacción del acta y su agregación al expediente.

Precisado el objeto de la prueba y los distiritos momentos de esta, se desprende que el Juez puede o no admitir una prueba en su condición de director del proceso. Esta no es desde luego una facultad arbitraria que la ley concede al juzgador, ella debe ajustarse a ciertos principios procesales que dan validez a su decisión, los conceptos de pertinencia, impertinencia, admisibilidad e inadmisibilidad e inutilidad de la prueba, son suficientes para precisar con toda amplitud los alcances y limitaciones de esta facultad jurisdiccional.

Una prueba es pertinente cuando versa sobre cuestiones que son materia de controversia. Si se discute en juicio el pago de una deuda de dinero, será pertinente el recibo que acredite que dicha suma ha sido pagada oportunamente. Una prueba es impertinente cuando se refiere a hechos que no son materia de controversia. En el ejemplo anterior sería impertinente que el actor pretendiera acreditar que un tercero es pariente del demandado. Una prueba es admisible cuando es capaz de acreditar una cuestión controvertida. Será prueba admisible la confesión judicial en

(3) Couture - Fundamentos. -Ed. Aniceto Alcaló, pág. 129. parag. 4. 
un juicio ordinario, solicitada en cualquier estado de la causa, con las limitaciones del Art. 365, y por el contrario esta misma prueba serk inadmisible si se pretendiera ofrecerla por segunda vez en un juicio sumario. Esta falta de idoneidad no se concreta únicamente a la improcedencia por razón de procedimiento, puede extenderse aún a la incapacidad intrínseca del medio probatorio. Nuestra legislación procesal nada dice respecto a las pruebas inadmisibles $y$ es el Juez a quien corresponde dejarlas de lado al momento de dictar sentencia. No sudcede lo mismo con las pruebas impertinentes en que, por expresa disposición del Art. 399, el Juez está obligado a repelerlas por no concretarse al asunto que se litiga ni a los hechos aducidos en el juicio $y$ en que no ha convenido expresamente la parte $\alpha$ quien perjudican. Sensiblemente, en la práctica judicial, los jueces siempre admiten esta clase de pruebas y sólo en vía de oposición y a solicitud de parte, son rechazadas.

Hay una prueba que no es ni impertinente ni inadmisible y que no abstante el Juez no puede aceptarla. Es la llamada prueba inútil, porque su actuación carece de objeto. Una parte no puede ofrecer la declaración de un testigo para acreditar la ley de la gravedad, porque como hemos señalado los hechos evidentes no son materia de la prueba.

Atendiendo a la naturaleza del proceso las pruebas se dividen en penales y civiles. Por el grado de convicción los afiliados al sistema de las pruebas legales distinguen las plenas de las semi-plenas. Por el modo las pruebas son directas si con ellas se acredita el hecho que se quiero probar sin necesidad de recurrir a otros elementos auxiliares; e indirectas si requieren de estos elementos. Por la forma se distinguen las pruebas originales de las que no lo son; las primeras son las obtenidas de testigos oculares por ejemplo, y las segundas de los testigos que han tenido conocimiento del hecho no directamente sino por simples referencias. Con relación al tiempo las pruebas pueden ser constituídas y preconstituídas, las primeras dentro del proceso y las segundas con anterioridad a él. Estas últimas admiten una subdivisión: preconstituídas "ex parte" y proconstituídas "partibus" según que hayan concurrido a su formación una o ambas partes. Por último las pruebas históricas se distinguen de las críticas, en que las primeras se limitan a la observación del Juez en forma personal trente al hecho controvertido, mientras que las segundas necesitan de una operación lógica en virtud de la cual de un hecho conocido se llega por inducción a un hecho desconocido. Ejemplos de las primeras son las pruebas instrumentales. Caso típico de las segundas son las declaraciones testimoniales.

Para la valoración de todas estas pruebas se han ensayado varios sistemas. De ellos dos son antagónicos y el tercero intermedio, a saber: el sistema de la prueba libre o de la libre convicción, el de la prueba tasada - legal y el de la sana crítica o mixto.

El sistema de la prueba libre o de la libreconvicción otorga al Juez amplia libertad en la apreciación de la prueba. No se ajusta a un criterio 
legăl y su eficacia está librada a la valoración personal del juzgador. Este sistema faculta al Juez a hacer mérito de hechos que no han sido probados, de simples circunstancias. Desconoce el principio procesal que ya hemos enunciado, de que el Juez está obligado a fallar con arreglo a lo alegado y probado por las partes. El Juez amparado en su libre convicción para apreciar las pruebas se convierte en un déspota. La injusticia se trasmuta en un instrumento de la arbitrariedad y desaparecen todas las garantías de que debe estar rodeado un proceso judicial.

Reaccionando contra este sistema, surge en España el denominado de las pruebas legales, en el cual al Juez se le indica el grado de eficacia o el valor probatorio de cada prueba. Se anticipa al proceso intelectual del Juez, quien resulta en buena cuenta un autómata. La prueba tasada no depende del Juez, se encuentra regulada por la ley, y éste debe aplicarla inexorablemente.

Una demostración del excesivo rigorismo de las pruebas tasadas se encuentra en el Libro IV, Tit. VII. Ley XXXII del Espéculo. Según este texto legal, los ancianos debían ser más creídos que los jóvenes "porque vieron más y pasaron más las cosas"; el hidalgo debía ser más creído que el villano "porque se guarda más de caer en vergüienza por sí y por su linaje"; el rico debe ser más creído que el pobre "pues el pobre puede mentir por codicia o promesa". La misma glosa podríamos hacer de otros textos legales informados del mismo sistema.

Las pruebas legales fueron admitidas por las leyes canónicas a través del procedimiento bárbaro, y no obstante haberse propuesto excluir la arbitrariedad de los jueces, es también artificial por cuya razón ha sido abandonado por las legislaciones contemporáneas. "El sistema de la prueba legal padece de un defecto fundamental que es el de consagrar una oposición antinatural entre el conocimiento humano y el jurídico" (4). El progreso de la ciencia procesal ha llevado a convencer que ninguno de los dos sistemas respondía a los fines de la justicia. El de la libre convicción convierte el procedimiento en una arbitrariedad por la amplitud de facultades que se otorga al Juez. El de la prueba tasada reconoce la incompetencia del Juez y razona por él. Se hizo entonces necesario un tercer sistema: el de la sana crítica o mixto, que ha sido aceptado por la legislación procesal de la mayoría de las naciones.

El sistema de la sana crítica devuelve al magistrado sus facultades tradicionales, controlándolas. El Juez falla con arreglo al mérito de las pruebas actuadas, pero sin atribuir en forma preestablecida un valor indiscutible a determinadas pruebas, como sucedía en el sistena de la prueba legal; $\mathrm{Y}$ contrariamente no puede hacer mérito sino de las pruebas que le han presentado las partes o que él ha mandado actuar de oficio, dejando de lado toda consideración o conocimiento personal sobre el asunto controvertido.

(4) Roberto de la Plaza, Curso de Derecno Procesal Civil. Pág. 221-6. 
Examinando nuestro Código de Procedimientos Civiles encontramos la prueba tasada en los Arts. 378, 392, 396, 401 y 430, que se refieren $\alpha$ la confesión, juramento decisorio, inspección ocular, instrumentos públicos e instrumentos privados reconocidos judicialmente. La libre convicción es recogida en el Art. 433 y la sana crítica en los Artículos 431, 490 y 504, que se refieren a los documentos privados reconocidos sólo por los testigos instrumentales $\circ$ por personas que no son parte en el juicio, a la prueba testimonial, y a los dictómenes periciales.

Los medios de prueba que autoriza nuestra legislación procesal civil son: la confesión que es la declaración en juicio hecha por alguna de las partes relacionada con las cuestiones cuya consecuenia juríaica es desfavorable para el que la presta. Puede ser expresa cuando se produce a solicitud de la contra parte y por intermedio del Juzgado, observando las formalidades de ley; y ficta cuando la supone el Juzgador en caso de inconcurrencia reiterada del obligado que se coloca en la condición de rebelde. Se considera por algunos tratadistas que también es confesión todo lo que expresan las partes en sus recursos, por contraposición a la confesión provocada, que puede $\alpha$ su vez ser a petición de parte 0 de oficio por el Juez. Nuestra Ley procesal civil dispone (Art. 378) que la confesión prueba plenamente contra el que la presta, siguiendo como se ha indicado, el sistema de la prueba tasada, lo que no sucede con la confesión tácita que puede ser enervada con otros medios de prueba, que si no se producen dejan inalterable la tasa fijada por la ley.

El Proyecto de Código de Procedimiento Civil de 1949 en el Art. 492, establece que la confesión expresa prueba contra el que la presta, suprimiendo acertadamente la palabra "plenamente", empero en su última parte agrega que la confesión ficta será apreciada por el Juez en la sentencia, compulsándola con las demós pruebas. No estimarmos feliz esta añadidura, ya que frente a la alternativa, quien ha sido llamado a prestar confesión preferirá en muchos casos que lo den por confeso, antes de exponerse a contestar determinadas preguntas que le harían perder el litigio, porque sabe que esa confesión tácita será compulsada con otras pruebas convirtiéndose así este medio probatorio en un arma favorable a los litigantes de mala fe, al haber sido despojada de su carácter de sanción contra la parte rebelde a los mandatos del Juzgador.

La inspección ocular es un medio de prueba que contribuye poderosamente al conocimiento directo de la verdad, nos dice la Exopsición de motivos de nuestra ley procesal civil. Es el examen directo que hace el Juez sobre la cosa materia de la controversia, pudiendo ser auxiliado con testigos y peritos. En algunos códigos foráneos se denomina reconocimiento judicial y en otros inspección personal.

Otro medio de prueba interesante es la declaración de testigos. En Derecho, testigo puede ser la persona que necesita concurrir a determinados actos jurídicos para que tenga validez. Con el testigo se concurre al otorgamiento de un testamento o de una escritura pública cualquiera; o aquella que emite una declaración en juicio siguiendo las formalidades del rito pro- 
cesal. Este medio de prueba entre nosotros tiene un valor probatorio relativo, y por eso se ha establecido que el valor probatorio de las declaraciones testimoniales será apreciado por el Juez con sujeción a las reglas de la critica (Art, 490).

La prueba documental es legislada en nuestra ley procesal civil, bajo el rubro de instrumentos. Documento en términos generales es la representación material de un pensamiento. Pueden ser públicos o privados. Los documentos públicos son los expedidos por los notarios conforme a las leyes: los extendidos o cutorizados por los funcionarios o empleados públicos en ejercicio de sus funciones; los extendidos en los Registros de Estado Civil y los otorgados por el Juez de Paz por falta de notario, desde que se protocolizan (A,rt. 400). En algunos casos tienen el valor de instrumentos públicos los extendidos en las parroquias, de conformidad con la disposición contenida en el Art. 1827 del Código Civil.

Los instrumentos públicos pueden ser entonces, notariales, administrativos y judiciales. En España antiguamente se distinguía el documento público del auténtico. El primero era extendido por las personas encargadas de dar fe y el segundo por los funcionarios o autoridades en ejercicio de su cargo. Precisadas las características de los instrumentos públicos, es obvio que documentos privados son todas las otras formas de representar materialmente un pensamiento sin recurrir $\alpha$ formalidad alguna.

En el proceso no todos los hechos son presentados al Juez para ser examinados directamente por él, con el simple auxilio de sus conocimientos jurídicos. Hary hechos que necesitan ser observados por personas capacitadas para apreciarlos correctamente. Esta capacidad no puede ser otra que la proporcionada por el estudio y de experiencia, lo que determina la pruebor pericial, que en realidad es más bien un auxilio intelectual que se presta al Juez en su cuotidiana labor de administrar justicia. El perito es la persona hábil o práctica en una ciencia, arte u oficio y que por tal razón puede emitir dictámnes sobre las cuestiones que se ventilan ante los jueces y tribunales. $A$. est $\alpha$ capacidad general debe agregarse la imparcialidad y objetividad de sus apreciaciones, pues de otro modo se desnaturalizaría su importante misión de asesoría e ilustración. El perito no es un testigo, no se le solicita que relate un hecho, sino que lo interprete, lo que justifica que los peritajes deben ser apreciados por el Juzgador con arreglo al sistema de la sana crítica, para evitar que los peritos se conviertan en jueces.

Para concluir debemos intentar resolver el interrogante de si los medios de prueba que señala nuestra ley procesal son los únicos con que cuenta el juzgador o si, por el contrario, puede admitir otros. Vale decir, si los medios de prueba tienen un carácter taxativo o simplemente enunciativo. Si nos inclinamos por la primera tesis tenemos que aceptar que el Juez sólo puede admitir única y exclusivamente los medios probatorios consignados en el texto. Si nos afiliamos a la segunda tesis, debemos convenir en que el Juez puede permitir a las partes acudir a otros medios probatorios que no se indican expresamente en el texto.

Los que sostienen que los medios de prueba son taxativos invocan on su apoyo que la facultad de establecer medios de prueba es patrimonio de 
la ley y no del arbitrio judicial ni menos de las partes, y que si se traslada esta facultad al Juez se introduce el desorden en el proceso, ya que en ejecución de esa facultad las partes estarían en aptitud de ofrecer todas las pruebas que les dicte su antojo, con el agtravante de poder ser admitidas si el arbitrio judicial las considera convenientes a la solución de la controversia. Los adversarios de este sistema arguyen que los códigos no se promulgan todos los días y que ante esta evidencia sería absurdo que el Juez tuviera que rechazar un nuevo medio de prueba, porque no estó. expresamente consignado en la ley.

El sistema de la enumeración taxativa que es el que obviamente sigue nuestro Código de Procedimientos Civiles y han admitido invariablemente nuestros jueces y tribunales, es indudablemente el más acertado. La duración de un texto legal por más prolongada que sea no justifica la adopción del sistema de la enumeración enunciativa, por los graves inconvenientes que plantea. Tampoco lo justifica el avance de la ciencia, porque el Derecho que también es ciencia avanza paralelamente con las demás Y se adapta a los posibles descubrimientos de las ciencias físicas. Además dentro de la llamada prueba pericial se pueden encuadrar en forma ilimitada los nuevos medios de prueba derivados de cualquier avance de las ciencias naturales, como ha sucedido con las radiografías, huellas dactiloscópi-. cas y pericias grafométricas. 